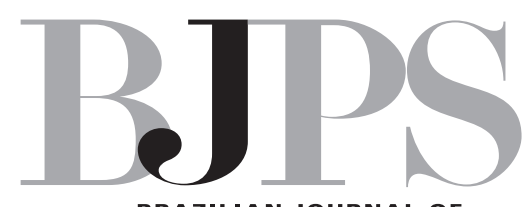

Brazilian Journal of

\title{
Ethics and development
}

In the past, ethical conduct was considered an integral part of academia and an unquestionable value, whereas today we see the mobilization of movements designed to prevent its demise. It may be a heartbreaking panorama, but one requiring urgent attention to reverse and educational practices to restore, rather than resorting to tears. To this end, we participated in a number of recent events for scientific editors, as representatives of the Brazilian Journal of Pharmaceutical Sciences: III Seminar for Scientific Editors of USP; The Libraries of USP, Ethics and Copyrights; XIII ENEC, National Meeting of Scientific Editors, on the theme Integrity and Ethics in scientific publishing, and the IV Satellite Seminar for Senior Editors, both organized by the Brazilian Association for Scientific Editors, ABEC, as well as the II Brazilian Meeting on Research Integrity, Science and Publication Ethics - II BRISPE, organized by Coppe/UFRJ. In these events, we identified the urgent need for greater engagement with the issue. According to Leite (2009), there is a consensus in the intellectual and academic world that pressure to publish, the semi-industrial organization of scientific research and the competition between academic journals have led to a lowering of ethical standards in the field, with increased frequency of fraud, manipulation and lapses in judgment. We cannot allow these situations to occur if we want to maintain the credibility of BJPS in the national and international scientific community.

We also know that a growing number of institutions are recognizing and promoting the scientific output of their teaching staff, insisting on publication of new articles that are oftentimes of questionable scientific merit. We observe that the concerns of Torresi et al. (2008) are still valid: pressures to increase the level of individual, institutional or countrywide publication cannot be used as an excuse for the lack of ethics in publications. In this respect, the Brazilian Journal of Pharmaceutical Sciences legitimizes its fight for quality and standing in the international community by flatly rejecting the use of self-citation to increase impact factors. Clearly, this is not in keeping with the 70-year history of publishing of the School of Pharmaceutical Sciences of the University of São Paulo.

We are proof that reputable conduct also generates results and development. Looking at the statistical data, we can identify clear growth in our visibility. In 2011, we recorded an increase in legitimate citations, compared to the previous year. These data are given in Table I, which also shows the number of citations of previous years, allowing us to evaluate the cited growth.

Aware of the risks involved in changing our editorial policies, in 2009 we adopted English as the official language, which, as expected, resulted in a reduction in the number of manuscripts received for evaluation 


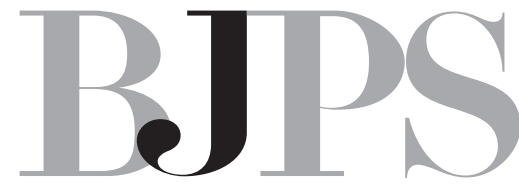

Brazilian Journal of

BRAZILIAN JOURNAL OF

PHARMACEUTICAL SCIENCES

TABLE I - Numerical Data - SciELO Basis - Content and Citations

\begin{tabular}{|l|c|c|c|c|c|c|c|c|c|c|}
\hline Year of publication & 2002 & 2003 & 2004 & 2005 & 2006 & 2007 & 2008 & $2009^{*}$ & 2010 & 2011 \\
\hline $\mathrm{N}^{\circ}$ of issues & 4 & 4 & 4 & 4 & 4 & 4 & 4 & 4 & 4 & 4 \\
\hline $\mathrm{N}^{\circ}$ of articles & 45 & 47 & 58 & 53 & 58 & 68 & 79 & 96 & 87 & 94 \\
\hline $\mathrm{N}^{\circ}$ of granted citations & 1924 & 1285 & 1827 & 1878 & 2153 & 2189 & 2902 & 2960 & 2902 & 2963 \\
\hline $\mathrm{N}^{\circ}$ of received citations & 17 & 21 & 20 & 21 & 32 & 55 & 96 & 7 & 20 & 44 \\
\hline Average articles per issue & 11.25 & 11.75 & 14.50 & 13.25 & 14.50 & 17.00 & 19.75 & 24.00 & 21.75 & 23.5 \\
\hline
\end{tabular}

* Changed to: Brazilian Journal of Pharmaceutical Sciences.

and possible publication in the Brazilian Journal of Pharmaceutical Sciences (Figure 1). However, in 2011, a significant recuperation of this particular measure was observed. Although the number of submissions has ultimately fallen, initially we have published the same average number of articles (Figure 2). Furthermore, there is increased interest from foreign authors, which indicates greater visibility of the journal internationally (Figure 3). On the other hand, this fact also means we must be extra vigilant against fraud, plagiarism, self-plagiarism, authorship and author responsibilities, duplicate submissions and other procedures that may infringe upon codes of ethics. We highlight the need to recognize and improve the system of peer review by increasing the number of specialists, and providing them with the tools to detect plagiarism, some available electronically, such as Google Search and Google Scholar, as well as the use of electronic tools such

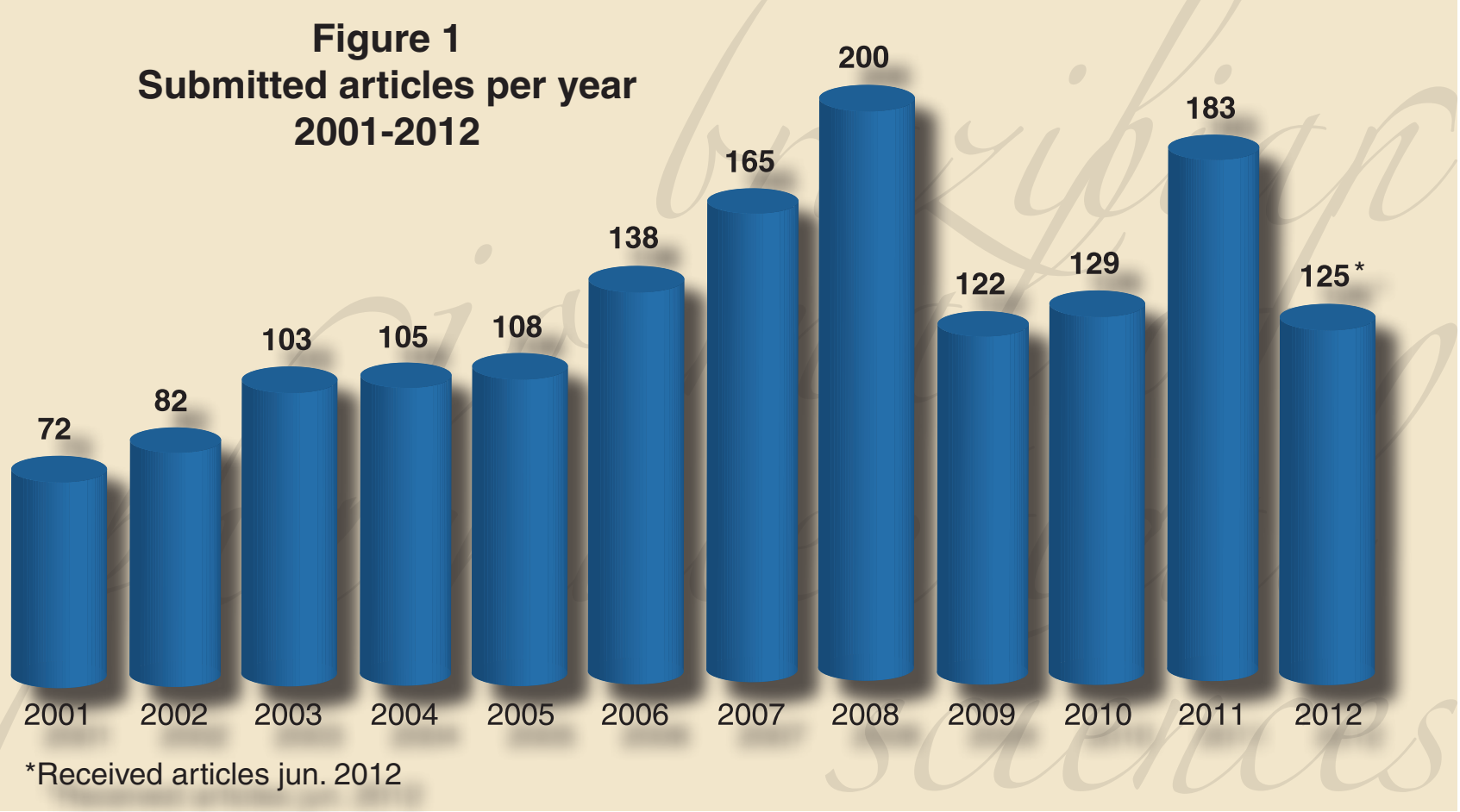




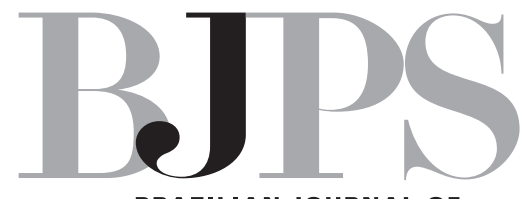

Brazilian Journal of

\section{Figure 2 \\ Published articles per year \\ 1993-2011

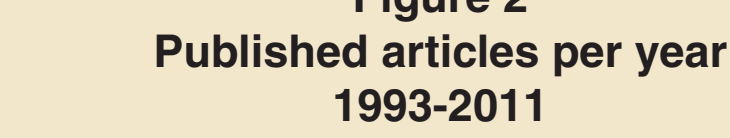

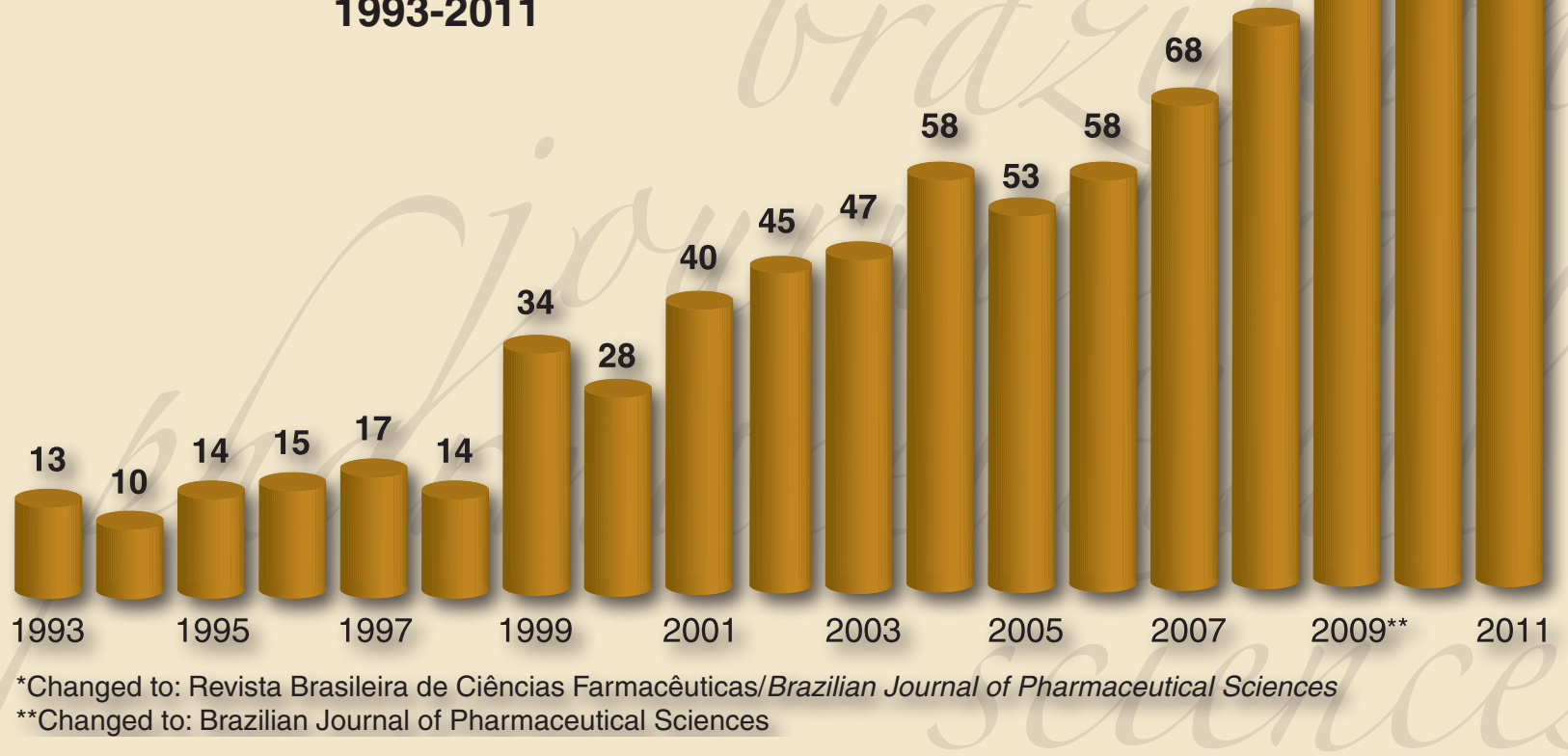

Figure 3

Origin of published articles per year 2001-2011 


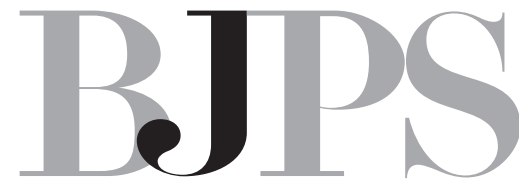

Brazilian Journal of

as CrossCheck®, in addition to other initiatives. We also stress the importance of making reviewers aware that human judgment will always be necessary. BJPS will spare no effort to encourage and support greater involvement of its reviewers in the pursuit of fraud.

It is important to note also that authors must display good conduct, as clearly defined in protocols of the Scientific Publication Ethics Committee (COPE), an entity founded in 1997, whose objective is to define better ethical practices for scientific publications, guidelines not only for authors, but also, and especially, for editors themselves, members of the editorial staff, owners of journals and publishers (COPE, n.d.).

The publishing of a scientific journal should be a source of pride not only for the editor and editorial staff, but also the entire scientific community which it represents and that, indirectly, consolidates its position as a reliable vehicle for dissemination.

Another pertinent point on this line of rigorous analysis of articles was the finding that, over the last four years, there has been an increase in the number of rejected manuscripts (Figure 4). Over these past four years, 361 articles were published. Of this total, around 91\% were original articles and roughly $9 \%$ were review articles (Figure 5).

The numerical data certainly show us the direction to take. New goals emerge that clamor to be implemented, such as the need to broaden the audience of BJPS internationally in the field of pharmaceuti-

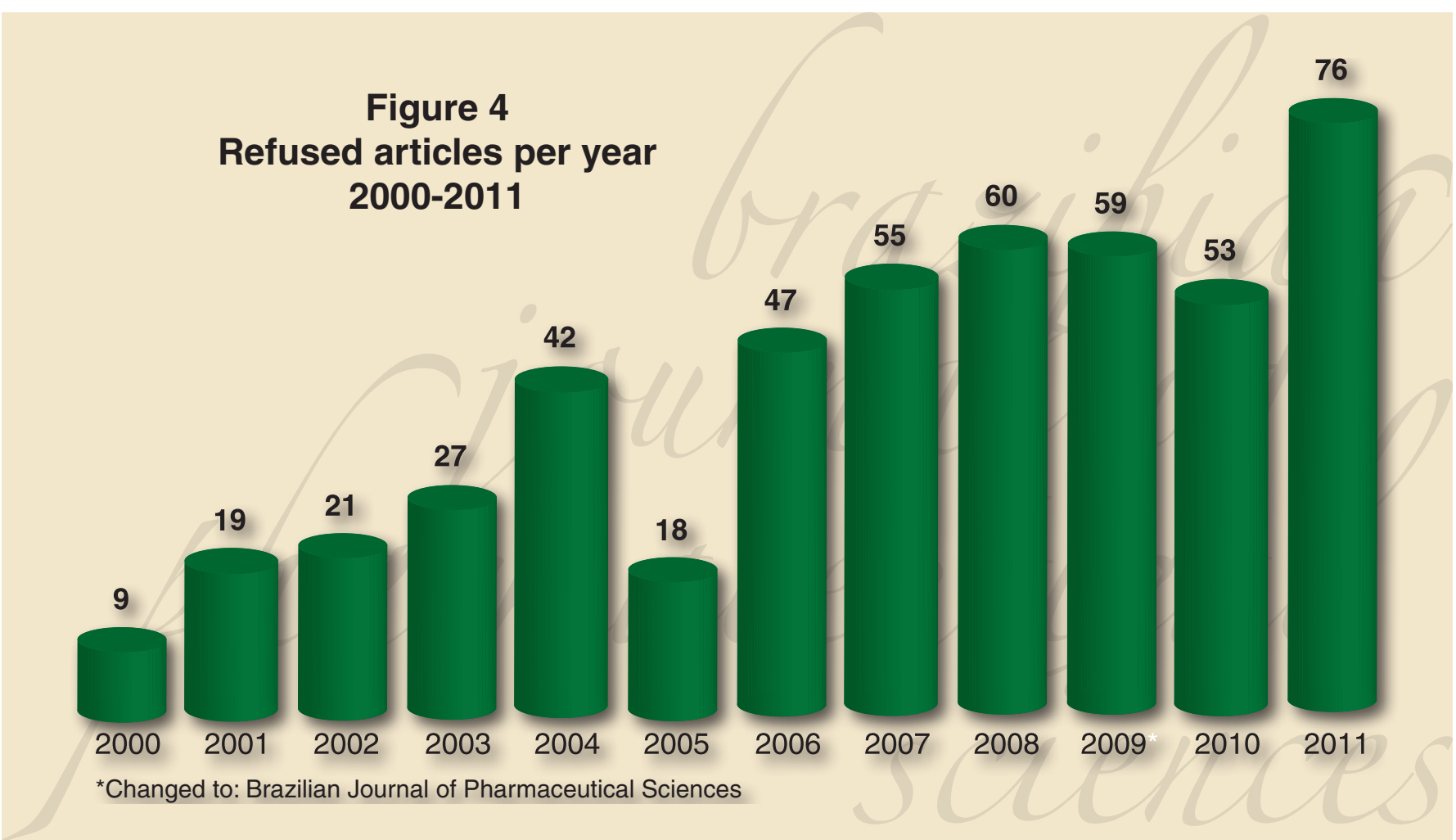



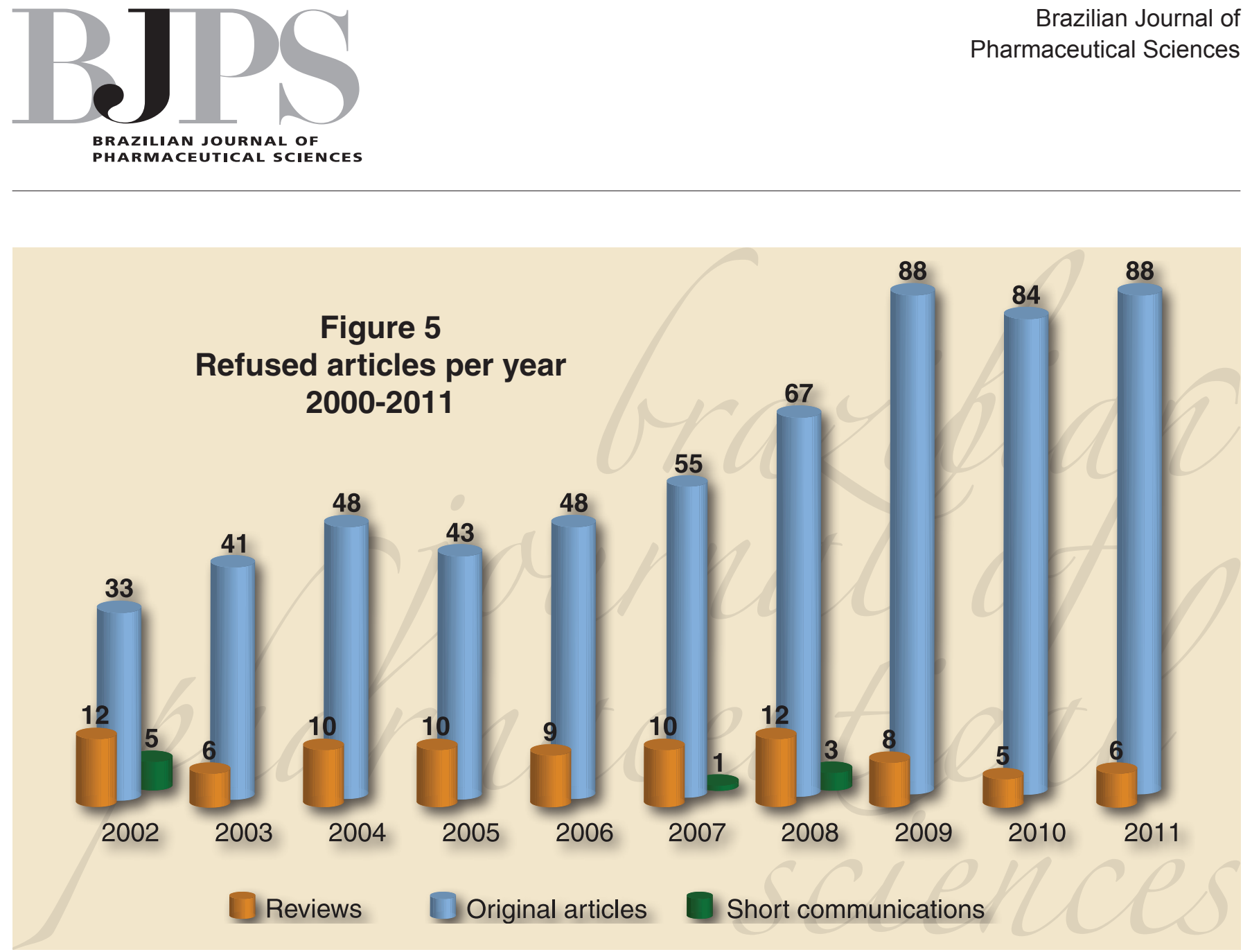

cal sciences; publication of special and thematic editions with the participation of foreign specialists; greater speed in the editorial process, specialized personnel training for the executive editorial board with a view to efficient continuity of services and effective automation of processes, among other challenges.

Nonetheless, we remain optimistic, the university is optimistic, and today Brazil is an emerging leader in research. These are indeed good times! It is up to us to take on leading roles in the development of pharmaceutical sciences in Brazil in a competent manner and contribute to real and sustainable growth!

As a partner in these endeavors, I would like to thank Prof. Dr. Elizabeth Igne Ferreira, scientific editor of the Brazilian Journal of Pharmaceutical Sciences, for the opportunities given me, for the respect of associate editors and the publication committee for the work carried out by the executive editorial board, for which I am responsible, and for the support and confidence of the Dean of the School of Pharmaceutical Sciences of the University São Paulo, Prof. Dr. Jorge Mancini Filho.

Dedication, persistence and conduct shall determine the flavor of the fruits and the pride of the harvest.

Leila Rangel de Carvalho Aranha

Executive Editor

Brazilian Journal of Pharmaceutical Sciences 


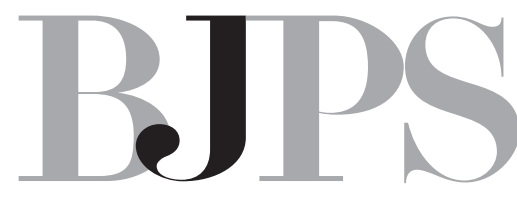

Brazilian Journal of Pharmaceutical Sciences

BRAZILIAN JOURNAL OF

PHARMACEUTICAL SCIENCES

\section{REFERENCES}

II BRAZILIAN MEETING ON RESEARCH INTEGRITY, SCIENCE AND PUBLICATION ETHICS. (II BRISPE). S.1., s.d. Available at: <http://www.proppi.uff.br/node/2023>. Acessed on: 17 may 2012.

COMITÊ de Ética em Publicações (COPE): Orientação sobre boa prática em publicações. Available at: $<$ http://www.fisiocirurgiauerj. org/Comite_de_Etica_em_Public_COPE.pdf $>$.Accessed on: 11 jun. 2012.

LEITE, M. Mais ética na academia. Available at: <http://cienciaemdia.folha.blog.uol.com.br/arch2009-11-01_2009-11-07.html>. Accessed on: 20 jun. 2012.

TORRESI, S. I. C.; PARDINI, V. L.; FERREIRA, V.F. Ética nas publicações científicas. Editorial. Quim. Nova, v.31, n.2, p.197, 2008. 